\title{
Perceived personal importance of exercise and fears of re-injury: a longitudinal study of psychological factors related to activity after anterior cruciate ligament reconstruction
}

Monique AM Gignac ${ }^{*}$, Xingshan Cao ${ }^{2}$, Subha Ramanathan ${ }^{3}$, Lawrence M White ${ }^{4}$, Mark Hurtig ${ }^{5}$, Monica Kunz ${ }^{6}$ and Paul H Marks ${ }^{7}$

\begin{abstract}
Background: Psychological perceptions are increasingly being recognized as important to recovery and rehabilitation post-surgery. This research longitudinally examined perceptions of the personal importance of exercise and fears of re-injury over a three-year period post anterior cruciate ligament $(A C L)$ reconstruction. Stability and change in psychological perceptions was examined, as well as the association of perceptions with time spent in different types of physical activity, including walking, household activities, and lower and higher risk for knee injury activities.

Methods: Participants were athletes, 18-40 years old, who underwent ACL reconstruction for first-time ACL injuries. They were recruited from a tertiary care centre in Toronto, Canada. Participants completed interviewer-administered questionnaires pre-surgery and at years one, two and three, postoperatively. Questions assessed demographics, pain, functional limitations, perceived personal importance of exercise, fear of re-injury and physical activities (i.e., walking; household activities; lower risk for knee injury activities; higher risk for knee injury activities). Analyses included fixed-effect longitudinal modeling to examine the association of a fear of re-injury and perceived personal importance of exercise and changes in these perceptions with the total hours spent in the different categories of physical activities, controlling for other factors.

Results: Baseline participants were 77 men and 44 women (mean age $=27.6$ years; SD $=6.2$ ). At year three, $78.5 \%$ of participants remained in the study with complete data. Fears of re-injury decreased over time while personal importance of exercise remained relatively stable. Time spent in walking and household activities did not significantly change with $\mathrm{ACL}$ injury or surgery. Time spent in lower and higher risk of knee injury physical activity did not return to pre-injury levels at three years, post-surgery. Greater time spent in higher risk of knee injury activities was predicted by decreases in fears of re-injury and by greater personal importance of exercise.

Conclusions: This study highlights not only fears of re-injury, which has been documented in previous studies, but also the perceived personal importance of exercise in predicting activity levels following ACL reconstructive surgery. The findings can help in developing interventions to aid individuals make decisions about physical activities post knee injury and surgery.
\end{abstract}

Keywords: Physical activity, Sports injuries, Anterior cruciate ligament reconstruction, ACL injuries, Fear of re-injury, Perceived importance of exercise, Exercise identity, Psychological factors, Osteoarthritis

\footnotetext{
* Correspondence: mgignac@iwh.on.ca

'Institute for Work and Health; Division of Health Care \& Outcomes Research,

Arthritis Community Research and Evaluation Unit, Toronto Western

Research Institute; Dalla Lana School of Public Health, University of Toronto,

Toronto, Canada

Full list of author information is available at the end of the article
}

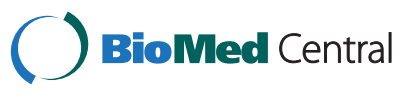

(C) 2015 Gignac et al.; licensee BioMed Central. This is an Open Access article distributed under the terms of the Creative Commons Attribution License (http://creativecommons.org/licenses/by/4.0), which permits unrestricted use, distribution, and reproduction in any medium, provided the original work is properly credited. The Creative Commons Public Domain Dedication waiver (http://creativecommons.org/publicdomain/zero/1.0/) applies to the data made available in this article, unless otherwise stated. 


\section{Background}

There is considerable interest in the role that psychological perceptions play in understanding whether individuals resume physical activities after a sports injury. This is largely due to evidence finding that physical recovery from an injury and psychological readiness to return to activities like sports do not always correspond [1-4]. Specifically, many individuals do not return to pre-injury levels of activity despite good surgical or rehabilitation outcomes [1,4-7]. Anterior cruciate ligament (ACL) injuries are a common cause for surgical intervention in sports medicine [8-10]. Estimates vary but suggest that, although $80 \%$ of individuals return to some type of sports by two years post ACL surgery, only about one to two thirds return to previous levels of activity $[1,4]$.

Common factors identified with lower levels of sport or physical activity post-ACL reconstruction are fears of re-injury and ongoing knee functional limitations [1-3,11-17]. However, studies examining fear of re-injury often have been cross-sectional, have focused on competitive sports in small samples of athletes or have been limited to the first 12 months post ACL reconstruction [1-4,12]. Fewer studies examine psychological perceptions over time, particularly changes in perceptions and their association with the type or level of activities.

In addition, there is little research on the personal importance of exercise to those who have sustained an ACL injury [11] despite studies finding that individuals for whom exercise is an important part of their identity are more likely to adopt and maintain physical activity [18-21]. This suggests that individuals with high personal importance of exercise may be more likely to resume previous levels of activity after ACL reconstruction. However, it is unclear what relationship exists between personal importance of exercise and fears of re-injury and whether, over time, higher exercise importance counteracts fears of re-injury and is associated with greater activity levels.

This study examined perceptions of the importance of exercise and fears of re-injury pre-surgery and at three year intervals post-ACL surgery. We examined whether perceptions were relatively stable or whether they changed post-surgery, as well as whether they were associated with physical activity over time, controlling for age, sex, body mass index (BMI), pain, and functional limitations [1-7,12,22-27]. Rather than focus on a single sport, we examined a range of activities [1,7]. Of interest was whether individuals would be less likely to return to potentially higher risk for knee injury physical activity than lower risk for knee injury physical activity, walking, and household activities. Research suggests that activities and sports that involve contact, pivoting, and greater loads on the knee (e.g., soccer, basketball, football) are more prone to ACL injuries and represent higher risk of knee injury activities [10,11,28,29]. Individuals may have greater fears of re-injury related to these types of activities and be less likely to engage in them. However, higher perceived importance of exercise may counteract these fears and be associated with greater time spent in higher risk of knee injury activities.

\section{Methods}

\section{Participants}

Respondents were recruited from April 2005- June 2007 in a large, tertiary care centre in Toronto, Canada. Participants experienced a first-time ACL injury and were between 18-40 years old. Male and female recreational, amateur and professional athletes were eligible for participation. Individuals were excluded if they had injured their ACL more than 6 weeks prior to their hospital visit or had reconstructive surgery scheduled for $>3$ months after their surgical intake interview. Patients also were excluded if they had a previous ACL injury or reconstruction, exhibited other bone pathology, pre-existing arthritis, or other systemic diseases. ACL reconstruction procedures were performed by one surgeon (PM) using a single incision, arthroscopic bone patellar tendon bone, transtibial reconstruction. All concomitant intra-articular pathologies were dealt with at the time of surgery (e.g., meniscal tears, plica, cartilage lesions). Femoral sided ACL graft fixation was performed with two bioabsorbable crosspins through the bone plug fixed with the knee at 90 degrees. A metal press fit interference screw was placed to secure the tibial side with the knee at 20-30 degrees flexion and with a posterior directed force on the anterior tibia and counterforce through stay sutures in the tibial bone plug. On occasion, there was graft size mismatch resulting in a longer graft which required tibial fixation using a trough with press fit fixation of the bone plug and a staple over top. Patients underwent a nine-month rehabilitation program with standard protocols. Regular rehabilitation appointments were held (e.g., postoperatively; 2-4 weeks; 5-10 weeks; $3-4$ months; 4-8 months; > 9 months). Rehabilitation included positioning and ambulation assessments (e.g., use of splints/braces), exercise activities that built toward sport-specific drills; and shared patient-practitioner goals for reducing swelling and pain, increasing range of motion, flexibility and cardiovascular fitness. Information about the study, screening for eligibility and informed consent occurred when patients attended a pre-surgical visit. Ethics approval was received from Sunnybrook Hospital, Toronto, Canada and informed, written consent was obtained from all participants.

\section{Procedure}

This study uses baseline and years one, two and three follow-up questionnaire data from a five-year longitudinal 
study examining outcomes from ACL reconstructive surgery. Participants completed a standard set of intervieweradministered questionnaires and provided clinical data for the study. Questionnaires were administered by a trained research assistant in a private room at the hospital and took approximately 45 minutes to complete. Baseline questionnaires were administered during a preoperative visit that was, on average, 40 days post-injury. Questionnaires were re-administered annually (Year one, Year two, Year three) postoperatively.

\section{Measures}

Physical Activity

The Minnesota Leisure-time Physical Activity Questionnaire (MLPAQ) assessed the type, frequency and intensity of involvement in different activities over a 12-month period [30]. The questionnaire asks about 54 different physical activities related to walking, conditioning, individual and team sports, racquet sports, water activities, winter activities, housework, home repair, and caregiving. It has been widely used and validated in epidemiological studies and interventions [31-34]. Participants can add activities if not listed in the questionnaire. For each activity, participants were asked whether they performed the activity and, if so, the average times per month and average minutes spent on each occasion. Using this, the total number of hours in different activities over the last year was calculated. Physical activities were grouped into three broad categories: household activities, walking activities, and sports and leisure physical activities. Caregiving activities (i.e., lifting a dependent) were omitted. Drawing on previous studies, sports and leisure activities were further divided into two groups: lower risk of knee injury and higher risk of knee injury activities $[10,11,28,29]$. Higher risk of knee injury activities were defined as contact sports, pivoting sports, activities with greater ground forces on landing or loads on the knee, and the potential for greater knee abduction or hyperextension. If an individual did not engage in any activities within a category they were assigned a score of zero hours in that activity. Two coders classified the activities independently. Inter-rater reliability for assignment into the two categories was high $($ kappa $=.88)($ Table 1$)$.

\section{Fear of re-injury}

The previously validated Anterior Cruciate Ligament Quality of Life (ACL-QOL) questionnaire measured perceptions of a fear of re-injury in the previous three months with a single item [35]. Participants were asked, "How fearful are you of reinjuring your knee?" Responses ranged from $0=$ extremely fearful to $100=$ no fear at all. Scores were reverse coded with higher values indicating greater fear of re-injury.
Table 1 Examples of lower and higher risk of knee injury physical activities reported by respondents

\begin{tabular}{ll}
\hline $\begin{array}{l}\text { Lower risk of knee injury } \\
\text { physical activities }\end{array}$ & $\begin{array}{l}\text { Higher risk of knee injury } \\
\text { physical activities }\end{array}$ \\
\hline Slow-pitch & Football \\
Pilates & Beach volleyball \\
Yoga & Rugby \\
Body sculpting & Gymnastics \\
Skipping & Lacrosse \\
Tai Chi & Cliff jumping \\
Kayaking & Hockey \\
Canoeing & Wrestling \\
White water rafting & Mountain biking \\
Physiotherapy exercises & Squash/racquetball \\
Golf & Trampoline \\
Elliptical training & Field hockey \\
Snow shoeing & Snowboarding \\
Stair climber & Martial arts \\
Paint ball & Tennis \\
Cycling & Waterskiing \\
Swimming & Soccer \\
Jogging & Ultimate Frisbee \\
Sailing & Basketball \\
Scuba diving & \\
Cross country skiing & \\
Tobogganing & \\
\hline
\end{tabular}

\section{Perceived Personal Importance of Exercise}

Perceptions of the personal importance of exercise to respondents were measured with a validated 9-item Exercise Identity Scale [36]. Sample items included, "I consider myself an exerciser" and "I need to exercise to feel good about myself." Responses were on a 5-point Likert-type scale from 1 = strongly disagree to 5 = strongly agree. Total scores were calculated by summing items. Higher scores reflected greater importance of exercise. Cronbach's alphas, a measure of the internal consistency of items, ranged from 0.91-0.93 across the different timepoints of data collection.

\section{Pain}

Nine items from the pain subscale of the Knee Injury and Osteoarthritis Outcome Score (KOOS) assessed the frequency and degree of pain in the previous week [37]. The KOOS has been widely used and validated [38]. Items examined pain associated with twisting/pivoting, walking on a flat surface, and going up/down stairs. Scores ranged from 0-100 with lower scores reflecting greater pain with activities [39]. Cronbach's alphas for the measure ranged from 0.82-0.87 across the time-points. 


\section{Sports and recreation activity limitations}

Functional limitations in sports and recreational activities were measured with 12 items from the recreational activities and sport participation subscale of the Anterior Cruciate Ligament - Quality of Life (ACL-QOL) questionnaire [35]. Responses were assessed over the previous three months on a visual analogue scale with an anchor of zero reflecting greater limitations, difficulties and concerns and an anchor of 100 indicating no limitations, difficulties or concerns. A total sports and recreational functional limitations score was calculated [40-43]. Cronbach's alphas ranged from 0.78-0.95.

\section{Demographic information}

Age, gender and type of sport in which the injury occurred were collected at baseline. Data for height and weight were collected annually and used to calculate Body Mass Index (BMI) scores.

\section{Analyses}

Sample descriptive statistics were calculated at baseline and at follow-ups, including frequencies, means, and standard deviations. Cross-wave comparisons examined means and 95\% confidence intervals (CI's) for the time spent in different categories of physical activity (i.e., walking, household activities, lower risk of knee injury activity, higher risk of knee injury activity) at baseline and Year one to three follow-up time-points. Comparisons across time also were made using means and $95 \%$ Cl's for fear of re-injury; personal importance of exercise; pain; sports and recreational activity limitations; and BMI. Pearson correlation coefficients examined the relationship between fear of re-injury and perceived exercise identity. To further describe individual differences in hours spent in lower and higher risk for knee injury physical activities at the Year three follow-up, respondents were divided into four groups based on median values for fear of re-injury and perceived personal importance of exercise (low fear of re-injury/low personal importance of exercise; low fear of re-injury/ high personal importance of exercise; high fear of re-injury/low personal importance of exercise; high fear of re-injury/high personal importance of exercise). Year three hours of lower and higher risk for knee injury physical activity were compared to baseline time spent in these activities across the groups.

Fixed-effect longitudinal models [44] examined predictors of time spent in: a) walking; b) household activities; c) lower risk of knee injury activity; and d) higher risk of knee injury activity. To disentangle temporal interrelationships among perceptions of a fear of re-injury and personal importance of exercise with the total hours spent in the different activities, psychological perceptions at an earlier wave were modeled on subsequent hours spent in the different categories of activity. This enabled a better understanding of potential causal relationships. To further disentangle effects of within-person and between-person changes of a fear of re-injury and personal importance of exercise, a personal-mean centering approach was used in the longitudinal models [45-48] and included the individual respondent mean for a fear of re-injury and personal importance of exercise, as well as within-person changes in the mean across time. Analyses controlled for age, gender, BMI, pain, and sports and recreational activity limitations. Data analyses used SAS V9.2. Longitudinal modeling was estimated using the PROC MIXED procedure with an unspecified covariance structure $($ TYPE $=\mathrm{UN})$.

\section{Results}

At baseline, there were 121 participants, 77 men (63.6\%) and 44 women ranging in age from 18-40 years (mean = 27.6 years; $\mathrm{SD}=6.2$ ) (Table 2). Over half of participants (53.8\%) reported injuries from soccer, skiing, and basketball; 19\% reported injuries as part of college/university teams; and the remainder of participants were recreational (53.7\%), amateur (19.8\%), and professional or minor professional (7.4\%) athletes. Overall BMI remained constant over time. Perceptions of a fear of re-injury and personal importance of exercise were not significantly correlated at baseline or at any follow-up ( $r$ values ranged from -0.17 to 0.11 , all $\mathrm{p}>.10$ ). At the Year three postsurgical follow-up, 97 participants (80.1\%) remained in the study. However, two participants were excluded from analyses because of missing data. Those dropping out of the study did not return for follow-up appointments after repeated attempts to contact them (Year one, $\mathrm{n}=3$; Year two, $\mathrm{n}=4$; Year three, $\mathrm{n}=5$ ) or had moved and were unable to travel to follow-up appointments (Year two, $\mathrm{n}=1$; Year $3, \mathrm{n}=11$ ).

Similar patterns of change emerged in pain, activity limitations, and fears of re-injury (Table 2). Scores were greatest at baseline (pre-surgery). The recall period for these variables largely captured post-injury experiences. Mean levels of pain, sports and recreation activity limitations and a fear of re-injury significantly decreased from baseline to Year one and from Year one to Year two. Reports of pain at Year two and Year three were low and not significantly different. Similarly, sports and recreation activity limitations and perceived fear of re-injury were lower at Years two to Year three with no further significant changes. Perceptions of the personal importance of exercise remained relatively constant over time with no significant mean changes across data collection waves.

Time spent walking and in household activities did not significantly differ from pre-surgery through Year one to three post-surgery follow-ups (Table 2). In general, 
Table 2 Means, standard deviations and 95\% confidence intervals of demographic, health, fear of re-injury, personal importance of exercise and time spent in physical activities at baseline and Year 1 to 3 follow-up

\begin{tabular}{|c|c|c|c|c|}
\hline & $\begin{array}{l}\text { Pre-ACL surgery } \\
\text { baseline }(n=121)\end{array}$ & $\begin{array}{l}\text { Year } 1 \text { follow-up } \\
\quad(n=115)\end{array}$ & $\begin{array}{l}\text { Year } 2 \text { follow-up } \\
\quad(n=107)\end{array}$ & $\begin{array}{l}\text { Year } 3 \text { follow-up } \\
\qquad(n=95)\end{array}$ \\
\hline & $\begin{array}{c}\text { Mean } \\
(95 \% \mathrm{Cl})\end{array}$ & $\begin{array}{c}\text { Mean } \\
(95 \% \mathrm{Cl})\end{array}$ & $\begin{array}{c}\text { Mean } \\
(95 \% \mathrm{Cl})\end{array}$ & $\begin{array}{c}\text { Mean } \\
(95 \% \mathrm{Cl})\end{array}$ \\
\hline \multicolumn{5}{|l|}{ Age in years (SD) } \\
\hline (range $18-40$ yrs) & $27.0(0.2)$ & & & \\
\hline \multicolumn{5}{|l|}{ Causes of initial injury $(n, \%)$} \\
\hline Soccer & $33(27.3 \%)$ & & & \\
\hline Basketball & $17(14.1 \%)$ & & & \\
\hline Skiing & $15(12.4 \%)$ & & & \\
\hline Ultimate frisbee/racquet & $11(9.1 \%)$ & & & \\
\hline \multicolumn{5}{|l|}{ Sports } \\
\hline Football/Rugby & $9(7.4 \%)$ & & & \\
\hline Baseball/Softball & $8(6.6 \%)$ & & & \\
\hline Volleyball & $6(5.0 \%)$ & & & \\
\hline Hockey & $5(4.1 \%)$ & & & \\
\hline Other & $17(14.0 \%)$ & & & \\
\hline \multicolumn{5}{|l|}{ Gender N (\%) } \\
\hline Male & 77 (63.6) & $73(63.5)$ & $67(62.6)$ & $59(62.1)$ \\
\hline Female & $44(36.4)$ & $42(36.5)$ & $40(37.4)$ & $36(37.9)$ \\
\hline Body mass index (BMI) & $\begin{array}{c}24.8 \\
(24.2,25.4)\end{array}$ & $\begin{array}{c}25.0 \\
(24.3,25.6)\end{array}$ & $\begin{array}{c}25.1 \\
(24.4,25.7)\end{array}$ & $\begin{array}{c}25.0 \\
(24.2,25.7)\end{array}$ \\
\hline Pain & $\begin{array}{c}66.9 \\
(64.3,69.6)\end{array}$ & $\begin{array}{c}87.5 \\
(85.6,89.5)\end{array}$ & $\begin{array}{c}91.8 \\
(90.1,93.5)\end{array}$ & $\begin{array}{c}91.9^{\mathrm{a}} \\
(89.8,94.1)\end{array}$ \\
\hline Sports and recreation activity limitations & $\begin{array}{c}10.8 \\
(9.0,12.5)\end{array}$ & $\begin{array}{c}61.2 \\
(56.6,65.7)\end{array}$ & $\begin{array}{c}74.3 \\
(70.0,78.6)\end{array}$ & $\begin{array}{c}78.7^{a} \\
(74.5,82.8)\end{array}$ \\
\hline Fear of re-injury & $\begin{array}{c}77.2 \\
(73.0,81.4)\end{array}$ & $\begin{array}{c}49.0 \\
(43.0,54.9)\end{array}$ & $\begin{array}{c}38.6 \\
(32.4,44.7)\end{array}$ & $\begin{array}{c}32.6^{\mathrm{a}} \\
(26.2,39.1)\end{array}$ \\
\hline Personal importance of exercise & $\begin{array}{c}38.2 \\
(37.1,39.3)\end{array}$ & $\begin{array}{c}36.0 \\
(34.7,37.4)\end{array}$ & $\begin{array}{c}36.4 \\
(35.0,37.8)\end{array}$ & $\begin{array}{c}36.2 \\
(34.9,37.6)\end{array}$ \\
\hline \multicolumn{5}{|l|}{ Physical activity } \\
\hline Walking & $\begin{array}{c}482.6 \\
(418.8,546.5)\end{array}$ & $\begin{array}{c}436.0 \\
(358.5,513.4)\end{array}$ & $\begin{array}{c}418.1 \\
(365.8,470.4)\end{array}$ & $\begin{array}{c}452.6 \\
(378.7,526.5)\end{array}$ \\
\hline Household activities & $\begin{array}{c}281.2 \\
(235.0,327.4)\end{array}$ & $\begin{array}{c}285.5 \\
(239.4,331.6)\end{array}$ & $\begin{array}{c}293.2 \\
(256.0,330.4)\end{array}$ & $\begin{array}{c}320.6 \\
(273.8,367.5)\end{array}$ \\
\hline Lower risk for knee injury & $\begin{array}{c}311.5 \\
(265.0,358.1)\end{array}$ & $\begin{array}{c}201.6 \\
(165.8,237.5)\end{array}$ & $\begin{array}{c}246.4 \\
(205.6,287.1)\end{array}$ & $\begin{array}{c}214.3^{\mathrm{b}} \\
(182.8,245.8)\end{array}$ \\
\hline Higher risk for knee injury & $\begin{array}{c}192.6 \\
(156.2,229.0)\end{array}$ & $\begin{array}{c}38.5 \\
(24.4,52.7)\end{array}$ & $\begin{array}{c}110.3 \\
(69.5,151.2)\end{array}$ & $\begin{array}{c}91.8^{\mathrm{a}} \\
(58.1,125.4)\end{array}$ \\
\hline Physical activities & & & & \\
\hline
\end{tabular}

Note: ${ }^{a}$ Indicates a significant difference between each wave of data $(p<.05)$, except Year 2 and Year 3;

${ }^{b}$ Indicates a significant differences $(p<.05)$ between baseline data and Year 1 , Year 2 and Year 3 follow-ups.

respondents spent greater amounts of time in lower risk of knee injury activities than higher-risk of knee injury activities. Time spent was greatest at baseline. This is not surprising as baseline activity captured activity in the previous 12 months, which was largely pre ACL injury. The average time spent in lower risk for knee injury activity was lowest at the Year one follow-up.
Surprisingly, time spent in these activities did not significantly increase at Year two and three follow-ups resulting in time spent in lower risk of knee injury physical activity being significantly lower Years one to three compared to baseline. Time spent in higher risk of knee injury physical activity was significantly lower at the Year one follow-up than all other waves of data 
collection. Although levels of higher risk for knee injury activity significantly increased at Years two and three, they remained significantly lower than pre-surgery (baseline) levels.

Longitudinal analyses did not reveal any factor to be significantly associated with walking (Table 3). Older participants and those whose personal importance of exercise scores increased over time spent significantly more time in household activities. Age was also associated with lower and higher risk of knee injury physical activity. Younger respondents spent significantly more time in these activities. Mean fear of re-injury scores did not significantly predict time spent in any type of activity. However, respondents who reported a greater decrease in their fear of re-injury over time spent significantly more time in higher risk of knee injury activities. Participants who reported greater importance of exercise spent significantly more time in both lower and higher risk of knee injury activities. Every 1 point increase on the scale measuring personal importance of exercise was associated with over twelve more hours of lower risk activities (12.47) and five more hours of higher risk activities (5.45).

To further describe time spent in lower and higher risk of injury activities, we categorized Year three and baseline activity levels into four groups (Table 4). The groups were created using Year three data and described individuals with: 1) low fear of re-injury/low personal importance of exercise $(n=33)$; 2) low fear of re-injury/ high personal importance of exercise $(n=25)$; 3) high fear of re-injury/low personal importance of exercise $(\mathrm{n}=13)$; and 4 ) high fear of re-injury/high personal importance of exercise $(n=20)$. Regardless of their fear of re-injury (low or high), respondents who were low on perceived importance of exercise had reduced time spent in higher risk of knee injury activities by over $60 \%$ at
Year three compared to baseline (58.8 hours $(\mathrm{SD}=60.0)$ versus 165.1 hours $(\mathrm{SD}=185.9)$; 64.1 hours $(\mathrm{SD}=80.6)$ versus 169.4 hours $(\mathrm{SD}=148.2)$ ). Fear of re-injury did not appreciably change activity levels among respondents with high personal importance of exercise at Year three. These respondents generally spent more than twice as much time in lower risk of knee injury activities than higher risk of knee injury activities. Their activity did not return to baseline levels for either lower or higher risk activities.

\section{Discussion}

This study examined the extent to which individuals returned to physical activity over three-years following ACL reconstruction and the association of psychological perceptions like a fear of re-injury and the personal importance of exercise with the type and extent of physical activity. The research adds to existing knowledge by longitudinally examining diverse types of activity instead of focusing solely on the sport where an ACL injury occurred. Activities included walking, household activities, and sports and recreational activities that may pose lower or higher risks for knee re-injury. Findings indicated that walking and household activities were not significantly changed by an ACL injury or surgery. However, the time spent in sports and recreational activities, regardless of the potential risk for knee re-injury, was diminished and did not return to pre-injury levels three years post-surgery. Greater time spent in lower and higher risk of knee injury activities could be explained by decreases in fears of re-injury and positive perceptions of exercise as important to one's self-identity. The findings highlight that fears of re-injury often change over time and that the perceived value of activities should be considered in research and interventions.

Table 3 Longitudinal mixed model analyses examining the association of demographic, pain, sports and recreation activity limitations, fear of re-injury and personal importance of exercise on subsequent time spent in walking, household activities, lower and higher risk for knee injury physical activities.

\begin{tabular}{|c|c|c|c|c|}
\hline & Walking & $\begin{array}{l}\text { Household } \\
\text { activities }\end{array}$ & $\begin{array}{c}\text { Lower risk for knee injury } \\
\text { physical activities }\end{array}$ & $\begin{array}{c}\text { Higher risk for knee injury } \\
\text { physical activities }\end{array}$ \\
\hline & $\beta$ (SE) & $\beta$ (SE) & $\beta$ (SE) & $\beta$ (SE) \\
\hline Age & $-2.64(3.98)$ & $5.49(2.55)^{*}$ & $-5.78(2.08)^{* *}$ & $-2.58(0.96)^{* *}$ \\
\hline Gender & $1.39(55.41)$ & $48.86(35.56)$ & $-0.81(29.84)$ & $-21.93(13.91)$ \\
\hline Body mass index & $-1.81(7.13)$ & $-3.44(4.51)$ & $4.83(3.62)$ & $0.75(1.77)$ \\
\hline Pain & $-0.46(1.82)$ & $0.30(1.11)$ & $1.23(0.70)$ & $0.47(0.36)$ \\
\hline Sports and recreation activity limitations & $0.94(0.98)$ & $1.10(0.60)$ & $-0.12(0.37)$ & $0.43(0.27)$ \\
\hline Mean fear of re-injury & $-0.29(1.15)$ & $0.82(0.74)$ & $-0.76(0.59)$ & $-0.27(0.29)$ \\
\hline Change in fear of re-injury & $0.66(0.96)$ & $1.04(0.56)$ & $-024(0.35)$ & $-0.72(0.22)^{* *}$ \\
\hline Mean personal importance of exercise & $3.68(4.04)$ & $-2.37(2.59)$ & $10.75(2.23)^{* *}$ & $3.84(1.02)^{* *}$ \\
\hline Change in personal importance of exercise & $2.46(6.01)$ & $11.67(3.52)^{* *}$ & $0.62(2.28)$ & $-0.28(1.43)$ \\
\hline
\end{tabular}

Note: $\beta=$ standardized regression coefficient; SE = standard errors; ${ }^{*} \mathrm{p}<.05 ;{ }^{* *} \mathrm{p}<.01$

Coefficients were estimated using REML under PROC MIXED, SAS 9.2. 
Table 4 Mean hours spent in lower and higher risk for knee injury activities for respondents with low/high fear of re-injury and low/high personal importance of exercise at the Year $\mathbf{3}$ follow-up compared to baseline

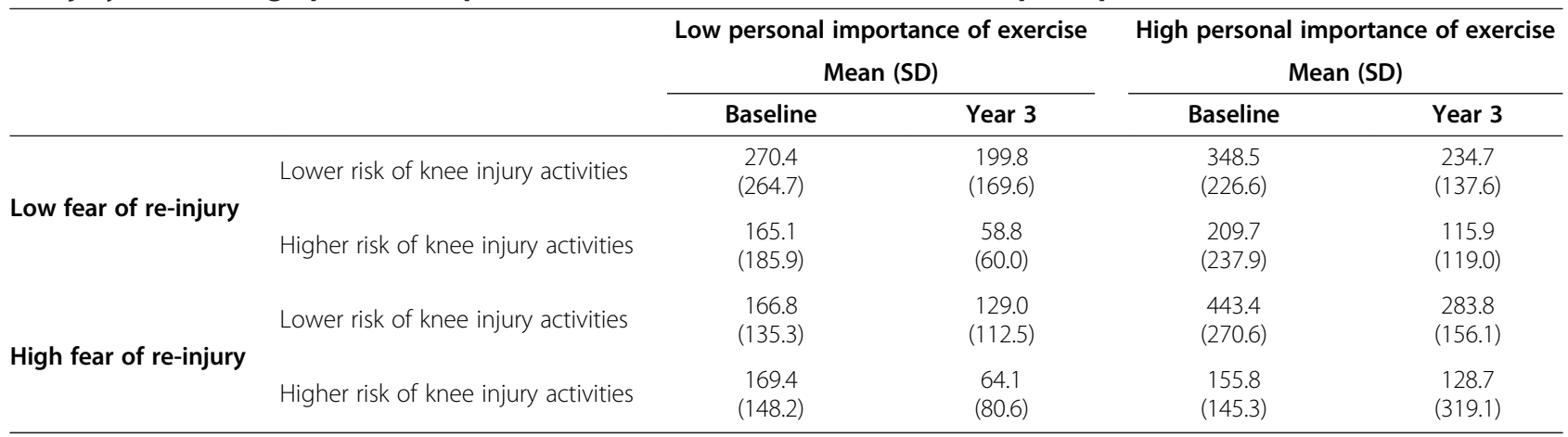

Note: $\mathrm{SD}=$ standard deviation.

Note: Low fear of re-injury/low personal importance of exercise $n=33$.

Low fear of re-injury/high personal importance of exercise $n=25$.

High fear of re-injury/low personal importance of exercise $n=13$.

High fear of re-injury/high personal importance of exercise $n=20$.

Similar to other studies, patients reported minimal pain and high levels of knee function post-recovery from surgery. With little variability in pain and function, it's not surprising that these factors were not related to time spent in activities. However, other studies with a greater range of functional limitations have demonstrated the importance of pain and function to activity levels $[1,3,7,12]$.

Age was significantly associated with time spent in activities. Younger respondents reported more time in lower and higher risk of knee injury activities and older participants reported more time spent in household activities. Given age similarities in pain, function and psychological perceptions and that the participants were relatively young, age differences may reflect changes to role demands and time available for activities. Ages 18-40 years are a period of considerable transition in role responsibilities. Individuals often work full-time and take on increased responsibilities for family and household chores. Previous studies have highlighted social roles and age transitions to understand the impact of health on activity participation [49-52]. Yet, normative changes in physical activity have not been examined as a factor explaining the failure to return to baseline activity levels post ACL reconstruction. Future studies would benefit from examining demographic variables like employment, marital status, and number of children, as well as respondents' perceptions of the time they have available for sports and exercise to further understand whether lower levels of engagement in activity is related to role demands.

The longitudinal design of this study helped better understand perceived fear of re-injury. Previous studies show that fears are associated with activity levels $[1-3,11,14,17,50]$. Yet, fears of re-injury were not significant in predicting activity levels longitudinally. Instead, changes in perceptions, particularly greater decreases in fears were related to greater levels of higher risk of knee injury activities. These findings provide more precision in understanding the importance of a fear of re-injury in ACL reconstruction. However, additional studies would be beneficial in gaining greater depth of understanding, especially using multi-item assessments [53] that could provide insight into why some athletes report greater reductions in fears; whether intervention efforts can reduce fears and increase activity levels; and whether increases in activities that are higher risks for knee injuries are desirable in athletes.

Also predictive of activity was the personal importance of exercise. Greater importance at any one time-point was significantly associated with more time spent in lower and higher risk of knee injury activities at later time-points. This perception was unrelated to fears of re-injury. Few studies have looked at attitudes toward exercise at an individual-difference or personality level [4], although interest is increasing with new measures examining personal importance of sport [54]. Additional descriptive information that examined activities for individuals who were low and high on personal importance of exercise further highlighted the findings. Individuals for whom exercise was not as important spent about half the hours in higher risk of injury activities than those who reported high importance of exercise. Although activity levels did not return to baseline, the findings point to differences in the value individuals place on exercise as critical in understanding returning to and sustaining sports and activity [1-4]. Of interest is what this means for future outcomes and the potential for reinjury or progression of joint damage, including the development of OA. Currently, data are lacking about the optimum level of activity, especially for higher risk of knee injury activities, following surgery. It's not 
clear whether individuals with higher personal importance of exercise might be more likely to ignore clinical recommendations or engage in activities to the extent that they may do additional damage. Longitudinal research is needed to examine these issues.

Several limitations need to be acknowledged in this research. Although activities were divided into lower and higher risk for knee injury and this helped understand subsequent activity levels, categorization of activities may not always be clear and may obscure other complexities related to the activities (e.g., skill levels). Moreover, although participants were followed for three years post-surgery, additional time to monitor activity levels and assess changes to joint structures and function is needed to explain why participants did not return to lower risk for injury activities and to assess psychological perceptions in greater detail. Data assessing objective levels of activity would also be beneficial as recall or reporting biases may have influenced physical activity reports. Finally, as noted previously, it would be useful to include new psychological measures assessing fear of re-injury at a multi-level, and sportspecific perceptions of importance, as well as a greater range of demographic variables to better understand the role of activity within the broader context of an individual's roles and responsibilities.

\section{Conclusions}

This study highlights the importance of changes in fears of re-injury and the personal importance of exercise when predicting subsequent activity levels following ACL reconstructive surgery. It shows that, although some activities like walking and household chores are largely unaffected by ACL injuries and reconstruction, many individuals do not return to previous activity levels, even for lower risk of knee injury activities. Moreover, changes in fears of re-injury were not related to all types of activity, but only higher risk of knee injury activities. This suggests that fears may not always be a barrier to activity. Finally, age differences in activity levels may reflect changes in normative role demands (e.g., more time needed for employment) and should be examined in greater detail, as well as controlled for in longitudinal analyses. These findings may be helpful in clinical and community settings to develop interventions aimed at better enabling individuals to make decisions about participation in activities after injuries.

\section{Competing interests}

The authors declare that they have no competing interest.

\section{Authors' contributions}

Conception and design: MAMG, MH, LMH, PHM. Acquisition, collection, \& assembly of data: PHM, MK, MH, LMW, MAMG, XC. Analysis \& interpretation of data: MAMG, XC, SR, MK, MH, LMW, PHM. Drafting, critical revision, \& final approval of the article: MAMG, XC, SR, PHM, LMH, MK, MH.

\section{Acknowledgements}

Our thanks go to the many participants who readily gave up their time to assist us with this research.

This research was funded by grants from the Canadian Institutes of Health Research (CIHR) (\#QNT 68722) and by the Canadian Arthritis Network, a Networks of Centres of Excellence.

\section{Author details}

${ }^{1}$ Institute for Work and Health; Division of Health Care \& Outcomes Research, Arthritis Community Research and Evaluation Unit, Toronto Western Research Institute; Dalla Lana School of Public Health, University of Toronto, Toronto, Canada. ${ }^{2}$ Arthritis Community Research and Evaluation Unit, Toronto Western Research Institute, Toronto, Canada. ${ }^{3}$ Postdoctoral Fellow, Faculty of Kinesiology and Physical Education, University of Toronto, Toronto, Canada. ${ }^{4}$ Joint Department of Medical Imaging, Faculty of Medicine, University Health Network, Mount Sinai Hospital, Women's College Hospital, University of Toronto, Toronto, Canada. ${ }^{5}$ Ontario Veterinary College, University of Guelph, Guelph, Canada. ${ }^{6}$ Division of Orthopaedic Surgery, Sunnybrook Health Sciences Centre, Toronto, Canada. ${ }^{7}$ Division of Orthopaedic Surgery, Faculty of Medicine, Sunnybrook Health Sciences Centre, University of Toronto, Toronto, Canada.

Received: 17 July 2014 Accepted: 9 January 2015

Published: 21 January 2015

\section{References}

1. Ardern CL, Webster KE, Taylor NF, Feller JA. Return to sport following anterior cruciate ligament reconstruction surgery: a systematic review and meta-analysis of the state of play. Br J Sports Med. 2011;45(7):596-606.

2. Ardern CL, Taylor NF, Feller JA, Whitehead TS, Webster KE. Psychological Responses Matter in Returning to Preinjury Level of Sport After Anterior Cruciate Ligament Reconstruction Surgery. Am J Sports Med. 2013;41:1549. doi:10.1177/0363546513489284.

3. Kvist J, Ek A, Sporrstedt K, Good L. Fear of re-injury: a hindrance for returning to sports after anterior cruciate ligament reconstruction. Knee Surg Sports Traumatol Arthrosc. 2005;13(5):393-7.

4. Rosenberger PH, Jokl P, Ickovics J. Psychosocial factors and surgical outcomes: an evidence-based literature review. J Am Acad Orthop Surg. 2006;14(7):397-405.

5. Kessler MA, Behrend H, Henz S, Stutz G, Rukavina A, Kuster MS. Function, osteoarthritis and activity after ACL-rupture: 11 years follow-up results of conservative versus reconstructive treatment. Knee Surg Sports Traumatol Arthrosc. 2008;16(5):442-8.

6. Lentz TA, Zeppieri G, Tillman SM, Indelicato PA, Moser MW, George SZ, et al. Return to Preinjury Sports Participation Following Anterior Cruciate Ligament Reconstruction: Contributions of Demographic, Knee Impairment, and Self-report Measures. J Orthop Sports Phys Ther. 2012;42(11):893.

7. Ross MD, Irrgang JJ, Denegar CR, MCCloy CM, Unangst ET. The relationship between participation restrictions and selected clinical measures following anterior cruciate ligament reconstruction. Knee Surg Sports Traumatol Arthrosc. 2002;10(1):10-9.

8. Brewer BW, Van Raalte JL, Cornelius AE, Petitpas AJ, Sklar JH, Pohlman MH, et al. Psychological factors, rehabilitation adherence, and rehabilitation outcome after anterior cruciate ligament reconstruction. Rehabil Psychol. 2000;45(1):20.

9. Linko E, Harilainen A, Malmivaara A, Seitsalo S. Surgical versus conservative interventions for anterior cruciate ligament ruptures in adults. Cochrane Database Syst Rev. 2005;Issue2; Art. No:CD001356. doi:10.1002/14651858. CD001356.pub3.

10. Griffin LY, Agel J, Albohm MJ, Arendt EA, Dick RW, Garrett WE, et al. Noncontact anterior cruciate ligament injuries: risk factors and prevention strategies. J Am Acad Orthop Surg. 2000;8:141-50.

11. Gianotti SM, Marshall SW, Hume PA, Bunt L. Incidence of anterior cruciate ligament injury and other knee ligament injuries: A national population-based study. J Sci Med Sport. 2009;12(6):622-7.

12. Czuppon S, Racette BA, Klein SE, Harris-Hayes M. Variables associated with return to sport following anterior cruciate ligament reconstruction: a systematic review. Br J Sports Med. 2014;48(5):356-64. 
13. Heijne A, Axelsson K, Werner S, Biguet G. Rehabilitation and recovery after anterior cruciate ligament reconstruction: patients' experiences. Scand J Med Sci Sports. 2008;18(3):325-35.

14. Lee DY, Karim SA, Chang HC. Return to Sports After Anterior Cruciate Ligament Reconstruction-A Review of Patients with Minimum 5-year Follow-up. Ann Acad Med Singapore. 2008;37(4):273.

15. Lohmander LS, Englund PM, Dahl LL, Roos EM. The long-term consequence of anterior cruciate ligament and meniscus injuries osteoarthritis. Am J Sports Med. 2007;35(10):1756-69.

16. Roos H, Ornell M, Gärdsell P, Lohmander LS, Lindstrand A. Soccer after anterior cruciate ligament injury-an incompatible combination? A national survey of incidence and risk factors and a 7-year follow-up of 310 players. Acta Orthop. 1995;66(2):107-12.

17. Tripp DA, Stanish W, Ebel-Lam A, Brewer BW, Birchard J. Fear of reinjury, negative affect, and catastrophizing predicting return to sport in recreational athletes with anterior cruciate ligament injuries at 1 year postsurgery. Rehabil Psychol. 2007:52(1):74.

18. Anderson DF, Cychosz CM. Exploration of the Relationship between Exercise Behavior and Exercise Identity. J sport behav. 1995;18(3):159-66.

19. Anderson DF, Cychosz CM, Franke WD. Association of exercise identity with measures of exercise commitment and physiological indicators of fitness in a law enforcement cohort. J Sport Behav. 1998;21(3):233-41.

20. Cardinal BJ, Cardinal MK. Changes in exercise behavior and exercise identity associated with a 14-week aerobic exercise class. J Sport Behav. 1997:20(4):377-86.

21. Gray JP, Soukup GJ, Sherals P. Influence of exercise identity on college students' physical fitness. Res Q Exerc Sport. 2007;78:A92.

22. Devos-Comby L, Cronan T, Roesch SC. Do exercise and self-management interventions benefit patients with osteoarthritis of the knee? A metaanalytic review. J Rheumatol. 2006;33(4):744-56.

23. Fransen M, McConnell S, Harmer AR, Van der Esch M, Simic M, Bennell KL. Exercise for osteoarthritis of the knee. Cochrane Database Syst Rev. 2015; Issue 1. Art. No:CD004376. doi:10.1002/14651858.CD004376.pub3.

24. Fransen M, McConnell S. Land-based exercise for osteoarthritis of the knee: a metaanalysis of randomized controlled trials. J Rheumatol. 2009;36(6):1109-17.

25. Kostka T, Bogus K. Independent contribution of overweight/obesity and physical inactivity to lower health-related quality of life in community-dwelling older subjects. Z Gerontol Geriatr. 2007;40(1):43-51.

26. Strine TW, Hootman JM, Chapman DP, Okoro CA, Balluz L. Health-related quality of life, health risk behaviors, and disability among adults with pain-related activity difficulty. Am J Public Health. 2005;95(11):2042.

27. Strine TW, Chapman DP, Balluz LS, Moriarty DG, Mokdad AH. The associations between life satisfaction and health-related quality of life, chronic illness, and health behaviors among US community-dwelling adults. J Community Health. 2008;33(1):40-50.

28. Hewett TE, Myer GD, Ford KR, Paterno MV, Quatman CE. The 2012 ABJS Nicolas Andry Award: The sequence of prevention: a systematic approach to prevent anterior cruciate ligament injury. Clin Orthop Relat Res. 2012;470(10):2930-40.

29. Smith HC, Vacek P, Johnson RJ, Slauterbeck JR, Hashemi J, Shultz S, et al. Risk Factors for Anterior Cruciate Ligament Injury A Review of the Literature ÇöPart 2: Hormonal, Genetic, Cognitive Function, Previous Injury, and Extrinsic Risk Factors. Sports Health. 2012;4(2):155-61.

30. Taylor HL, Jacobs Jr DR, Schucker B, Knudsen J, Leon AS, Debacker G. A questionnaire for the assessment of leisure time physical activities. J Chronic Dis. 1978;31(12):741-55.

31. Richardson MT, Leon AS, Jacobs DR, Ainsworth BE, Serfass R. Comprehensive Minnesota Leisure-Time Physical Activity Questionnaire. J Clin Epidemiol. 1994:47:271-81.

32. Nowak Z, Plewa M, Skowron M, Osiadlo G, Markiewicz A, Kucio C. Minnesota Leisure-Time Physical Activity Questionnaire as an additional tool in clinical assessment of patients undergoing percutaneous coronary interventions. J Hum Kinet. 2010;23:79-87.

33. van Poppel MNM, Chinapaus MJM, Mokkink LB, van Mechelen W, Terwee CB. Physical activity questionnaires for adults: a systematic review of measurement properties. Sports Med. 2010;49(7):565-600.

34. Neilson HK, Robson PJ, Friedenreich CM, Csizmadi I. Estimating activity energy expenditure: How valid are physical activity questionnaires. Am J Clin Nutr. 2008:87:279-91.
35. Mohtadi N. Development and validation of the quality of life outcome measure (questionnaire) for chronic anterior cruciate ligament deficiency. Am J Sports Med. 1998;26(3):350-9.

36. Anderson DF, Cychosz CM. Development of an exercise identity scale. Percept Mot Skills. 1994;78(3):747-51.

37. Roos EM, Roos HP, Ekdahl C, Lohmander LS. Knee injury and Osteoarthritis Outcome Score (KOOS): Validation of a Swedish version. Scand J Med Sci Sports. 1998;8(6):439-48.

38. Collins NJ, Misra D, Felson DT, Corssley KM, Roos EM. Measures of knee function. Arthritis Care Res. 2011;63(S11):S208-28

39. Roos EM. Knee Injury and Osteoarthritis Outcome Score (KOOS). The 2012 User's Guide to Knee Injury and Osteoarthritis Outcome Score (KOOS). 2012. http://wwwnu/KOOSusersguide2012 pdf. koos 2012Available from: URL: http://www.koos.nu/KOOSusersguide2012.pdf.

40. Grant JA, Mohtadi NG. Two-to 4-year follow-up to a comparison of home versus physical therapy-supervised rehabilitation programs after anterior cruciate ligament reconstruction. Am J Sports Med. 2010;38(7):1389-94.

41. Ramjug S, Ghosh S, Walley G, Maffulli N. Isolated anterior cruciate ligament deficiency, knee scores and function. Acta Orthop Belg. 2008;74(5):643.

42. Sutherland AG, Cooper K, Alexander LA, Nicol M, Smith FW, Scotland TR. The long-term functional and radiological outcome after open reconstruction of the anterior cruciate ligament. J Bone Joint Surg, British Volume. 2010;92(8):1096-9.

43. Tanner SM, Dainty KN, Marx RG, Kirkley A. Knee-Specific Quality-of-Life Instruments Which Ones Measure Symptoms and Disabilities Most Important to Patients? Am J Sports Med. 2007:35(9):1450-8.

44. Allison PD. Fixed effects regression methods for longitudinal data using SAS. Cary, NC: SAS Institute Inc:; 2005.

45. Curran PJ, Bauer DJ. The disaggregation of within-person and between-person effects in longitudinal models of change. Annu Rev Psychol. 2011;62:583.

46. Hoffman L, Stawski RS. Persons as contexts: Evaluating between-person and within-person effects in longitudinal analysis. Res Hum Dev. 2009;6(2-3):97-120.

47. Raudenbush SW. Hierarchical linear models: Applications and data analysis methods. 1st ed. Newbury Park, CA: Sage; 2002.

48. Singer JD, Willett JB. Applied longitudinal data analysis: Modeling change and event occurrence. New York, NY: Oxford University Press; 2003.

49. Alwin DF. Integrating varieties of life course concepts. J Gerontol Series B: Psychol Sci Soc Sci. 2012;67(2):206-20.

50. Kaptein SA, Backman CL, Badley EM, Lacaille D, Beaton DE, Hofstetter C, et al. Choosing where to put your energy: A qualitative analysis of the role of physical activity in the lives of working adults with arthritis. Arthritis Care Res. 2013;65(7):1070-6.

51. Gignac MAM, Backman C, Davis A, Lacaille D, Cao X, Badley EM. Social role participation and the life course in healthy adults and individuals with osteoarthritis: Are we overlooking the impact on the middle-aged? Soc Sci Med. 2013;81:87-93.

52. Hendricks J. Considering Life Course Concepts. J Gerontol B Psychol Sci Soc Sci. 2012;67(2):226-31.

53. Walker $\mathrm{N}$, Thatcher J, Lavallee D. A preliminary development of the re-injury anxiety inventory (RIAI). Phys Ther Sport. 2010;11:23-9.

54. Brewer BW, Cornelius AE, Stephan Y, Van Raalte JL. Self-protective changes in athletic identity following $A C L$ reconstruction. Psychol Sport and Exerc. 2010;11:1-5

doi:10.1186/2052-1847-7-4

Cite this article as: Gignac et al:: Perceived personal importance of exercise and fears of re-injury: a longitudinal study of psychological factors related to activity after anterior cruciate ligament reconstruction. BMC Sports Science, Medicine, and Rehabilitation 2015 7:4. 